\title{
Aposições restritivas e não restritivas: correlações pragmáticas e semânticas
}

DOI: http://dx.doi.org/10.21165/el.v49i2.2601

\author{
Monielly Saverio Serafim ${ }^{1}$ \\ Roberto Gomes Camacho²
}

\section{Resumo}

Este trabalho se debruça sobre o estudo das aposições restritivas e não restritivas no português escrito. Entende-se por aposições restritivas SNs como o poeta Drummond, a cor azul, FHC presidente e a cidade de São Paulo, o conceito de proletariado, o mês de janeiro. Por aposições não restritivas, entendem-se as construções prototípicas de aposição como Machado de Assis, o bruxo de Cosme Velho. O objetivo geral é aplicar critérios de formulação e de codificação que distingam essas aposições com base numa correlação entre aposições restritivas e construções classificacionais e entre aposições não restritivas e construções identificacionais cujos fundamentos teóricos se assentam na Gramática Discursivo-Funcional (HENGEVELD; MACKENZIE, 2008).

Palavras-chave: aposição; aposição restritiva; aposição não restritiva; construção identificacional; construção classificacional.

1 Universidade Estadual Paulista "Júlio de Mesquita Filho" (UNESP), São José do Rio Preto, São Paulo, Brasil; mony.serafım@gmail.com; https://orcid.org/0000-0002-6739-3799

2 Universidade Estadual Paulista "Júlio de Mesquita Filho" (UNESP), São José do Rio Preto, São Paulo, Brasil; roberto.camacho@unesp.br; https://orcid.org/0000-0002-8897-7953 


\title{
Close and loose appositions: pragmatic and semantic correlations
}

\begin{abstract}
This work focuses on close and loose appositions in written Portuguese. Close appositions are understood as NPs as o poeta Drummond (the poet Drummond), a cor azul (the color blue), FHC presidente (FHC president) and a cidade de São Paulo (the city of São Paulo), o conceito de proletariado (the concept of proletariat), o mês de janeiro (the month of January). Loose appositions are understood as prototypical constructions as Machado de Assis, o bruxo de Cosme Velho (Machado de Assis, the wizard of Cosme Velho). The goal of this paper is to identify the formulation and the coding parameters that distinguish both types of appositions based on a correlation between close apposition and classificational construction and between loose apposition and identificational construction whose theoretical foundations are based on Functional Discourse Grammar (HENGEVELD; MACKENZIE, 2008).
\end{abstract}

Keywords: apposition; close apposition; loose apposition; classificational construction; identificational construction.

\section{Introdução}

O termo aposição cobre um abrangente conjunto de construções nominais na literatura linguística. No âmbito da gramática tradicional, as aposições distinguem-se, normalmente, pelo critério formal, que indica a presença ou não de pausa bem definida entre os membros nominais da construção, como se vê em (1) e (2a-d).

(1) Eles, os pobres desesperados, tinham uma euforia de fantoches. (F. Namora, DT, 237.) (CUNHA; CINTRA, 2008, p. 170, grifos dos autores).

(2) a A cidade de Lisboa (CUNHA; CINTRA, 2008, p. 170, grifos dos autores).

b O poeta Bilac (CUNHA; CINTRA, 2008, p. 170, grifos dos autores).

c O rei D. Manuel (CUNHA; CINTRA, 2008, p. 170, grifos dos autores).

d O mês de junho (CUNHA; CINTRA, 2008, p. 170, grifos dos autores).

A ocorrência contida em (1) exemplifica a chamada aposição não-restritiva, cuja pausa é marcada, na escrita, por uma vírgula; já as contidas em (2a-d) ilustram casos de aposição restritiva, ou, ainda, aposto especificativo (CUNHA; CINTRA, 2008; BECHARA, 2009; KURY, 2011), que envolvem sintagmas com dois elementos nominais ligados ou não pela preposição de. 
As aposições são objeto de estudo de diversos linguistas, sem que haja consenso sobre aspectos semânticos e sintáticos de sua constituição. Autores como Fries (1952 apud MEYER, 1992), Francis (1958), Matthews (1981) e Lago (1991) consideram como aposição apenas sintagmas nominais correferenciais justapostos, posição que restringe às não restritivas as estruturas que estão no escopo do termo aposição. Quirk et al. (1985), por seu lado, assumem uma posição mais ampla, considerando como aposições estruturas de SNs correferenciais ou de SNs cuja referência de um nome esteja incluída na referência do outro. Assim como Quirk et al. (1985), Meyer (1992) também inclui estruturas de SNs correferenciais e não correferenciais em seu estudo sobre aposição no inglês, além de ampliar o conceito de aposição para contemplar também estruturas oracionais.

Outra divergência sobre essas estruturas diz respeito ao tratamento dado às relações sintáticas estabelecidas entre os membros apositivos. Alguns autores postulam que a relação sintática estabelecida entre eles é a de coordenação (HOCKETT, 1955) e outros, a de subordinação (TESNIÈRE, 1965). Além dessas posições, existem autores que assumem ser de interdependência a relação estabelecida entre os membros da aposição (LAGO, 1991). Por fim, há ainda os que assumem atitudes mais radicais, negando a presença de qualquer relação sintática entre os nomes (LONGRÉE, 1987 apud LAGO, 1991).

Essas divergências semânticas e sintáticas conduzem a uma separação das aposições em dois grandes grupos, o das aposições não restritivas e o das aposições restritivas. Embora também não haja consenso sobre as características das estruturas dentro de cada grupo, é possível generalizar algumas características presentes na maioria das definições. As aposições não restritivas (Machado de Assis, escritor brasileiro) são, em geral, caracterizadas como dois sintagmas correferenciais separados, na fala, por uma pausa e, na escrita, geralmente por uma vírgula, sendo de modificação a relação semântica estabelecida entre eles. Já as aposições restritivas são construções em que os elementos nominais estão justapostos (o escritor brasileiro Machado de Assis) ou ligados pela preposição de (a cidade de São Paulo) e sem correferencialidade, além de ser a relação semântica entre os membros nominais a de modificação e a relação sintática, a de subordinação.

A correferencialidade entre os itens nominais, o principal aspecto que diferencia essas estruturas, é fator determinante para que muitos linguistas não considerem as aposições restritivas como aposições de fato, por argumentarem que nelas há a ausência dessa propriedade semântica (LAGO, 1991; RODRÍGUEZ, 1989; TABOADA, 1978, TESNIÈRE, 1965).

No arcabouço teórico da Gramática Discursivo-Funcional, as aposições não restritivas, as restritivas sem elemento de ligação e as restritivas com de apresentam diferentes características pragmáticas, semânticas e morfossintáticas que permitem, a priori, uma subdivisão em grupos distintos. 
Nesse modelo, a aposição não restritiva consiste em uma estrutura no Nível Interpessoal (NI) com dois Subatos de Referência ( $R_{1}$ e $R_{\jmath}$ ), mas que, no Nível Representacional (NR), denotam uma única entidade $\left(\mathrm{x}_{\mathrm{i}}\right)$, como pode ser observado em (3):

$\begin{array}{lll}\text { (3) } & \text { Nl: } & \left(R_{1}\right) \quad\left(R_{\jmath}\right) \\ & N R: & \left(x_{i}\right)\end{array}$

Lula, ex-presidente do Brasil

As aposições restritivas sem elemento de ligação e as aposições restritivas com de, por outro lado, dispõem, no Nível Interpessoal, apenas de um Subato de Referência $\left(R_{1}\right)$ e denotam, correlativamente, no Nível Representacional, também uma única entidade $\left(\mathrm{x}_{\mathrm{i}}\right)$ como mostra (4).

(4) NI:

NR:

O ex-presidente Lula
$\left(R_{1}\right)$

$\left(x_{i}\right)$

Esse modo de representação implica a existência de uma relação de transparência, que se traduz em uma relação de um para um entre as unidades dos níveis Interpessoal e Representacional. Ao contrário, as aposições não restritivas, como observado em (3), que dispõem de uma relação de muitos-para-um entre os dois níveis de formulação (HENGEVELD, 2011), configuram uma relação opaca ou não transparente.

Sobre as aposições em português, os trabalhos de cunho funcionalista de Nogueira (1999, 2011, 2012) são referência no tratamento das aposições não restritivas e apresentam importantes generalizações de aspectos formais, funcionais e textual-discursivos desse tipo de construções no português. Em relação, especificamente, às aposições restritivas, destacamos o trabalho de Lemson (2016), que traz significantes considerações sobre a nuclearidade, correferencialidade e relações estabelecidas entre os itens nominais.

Diferentemente desses estudos prévios sobre o português, o objetivo deste trabalho é distinguir as aposições não restritivas das aposições restritivas mediante uma aproximação com predicados do tipo identificacional e do tipo classificacional, respectivamente, considerando como suporte teórico a Gramática Discursivo-Funcional ${ }^{3}$ e especialmente o texto de Keizer (2005). As ocorrências analisadas são extraídas de uma amostra de 36 textos retirados de 12 edições impressas da CartaCapital, revista de circulação nacional. Para fazer referência a uma ocorrência, entre parênteses, coloca-se

3 Este texto desenvolve um subtópico da dissertação de mestrado de Serafim (2019). 
o número da edição, a inicial do tipo de texto ( $\mathrm{R}$ para reportagens, E para editoriais e $\mathrm{O}$ para textos de opinião) ${ }^{4}$ e, por fim, a(s) página(s) em que o texto foi publicado. Foram analisados 102 casos de aposições restritivas, 90 dos quais de aposições sem conector e 12 de aposições restritivas com de.

Este texto acha-se organizado da seguinte maneira: a seção 2 trata do suporte teórico; a seção 3 dá um tratamento pragmático e semântico para as diferenças entre o tipo restritivo e o não restritivo de aposição; encerram o texto as Considerações finais em que se faz um balanço das principais conclusões.

\section{Suporte teórico: a Gramática Discursivo-Funcional}

Este trabalho adota uma perspectiva teórica baseada na Gramática Discursivo-Funcional (HENGEVELD; MACKENZIE, 2008), cuja organização, representada na Figura 1, consiste em uma orientação descendente, o que significa que o modelo contempla uma direção que parte da intenção do falante e se desenvolve até a articulação. A motivação dessa arquitetura se justifica no fato de que um modelo de gramática será tanto mais eficaz quanto mais sua organização se assemelhar ao processamento linguístico de um indivíduo (HENGEVELD; MACKENZIE, 2008).

4 Ressalta-se que tipo de texto não é em si um critério de análise, mas, por estarem esses tipos presentes em todas as edições da revista, considerar essa variação dá um grau maior de consistência à amostra, que serviu de base também a trabalhos anteriores de pesquisa dos autores. 
Figura 1. Esquema geral da GDF.

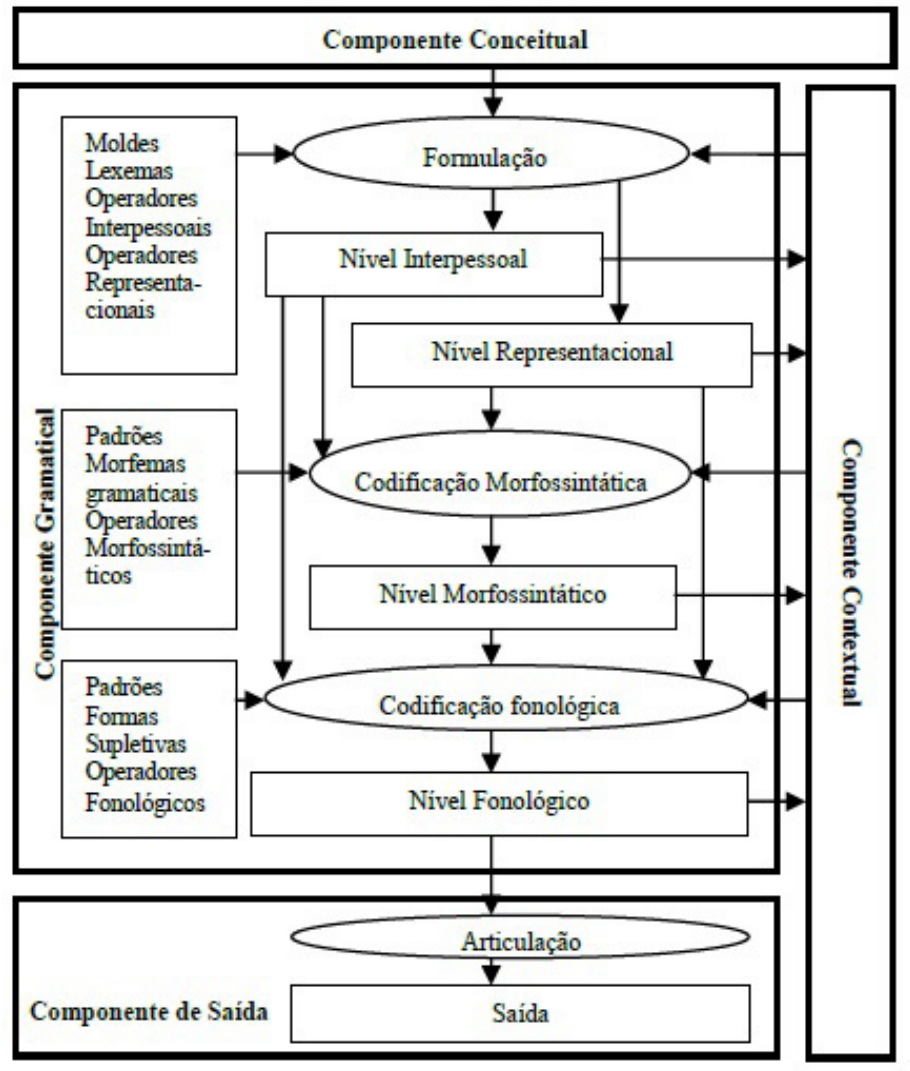

Fonte: Adaptado de Hengeveld e Mackenzie (2008, p. 13).

O modelo compreende a formulação de três componentes não gramaticais: o Componente Conceitual, o Componente de Saída e o Componente Contextual. Esses três componentes interagem com o Gramatical por meio de operações de Formulação e de Codificação. A Formulação considera as regras que determinam o que constitui ou não representações pragmáticas e semânticas válidas em uma língua; a Codificação considera as regras que convertem essas representações em representações morfossintáticas e fonológicas.

Dentro dos componentes, as elipses contêm as operações de formulação e de codificação, os quadrados contêm os primitivos usados nas operações e os retângulos contêm os níveis de representação produzidos pelas operações.

O Componente Conceitual é responsável pela intenção comunicativa e as representações mentais correspondentes. A operação de Formulação converte, no Componente Gramatical, essas representações mentais em representações pragmáticas e semânticas para os dois níveis mais altos, o Nível Interpessoal e o Nível Representacional, respectivamente. A operação de Codificação converte o conteúdo 
pragmático e semântico em unidades formais de natureza morfossintática (Nível Morfossintático) e de natureza fonológica (Nível Fonológico).

O Componente de Saída gera as expressões acústicas, escritas, ou de sinais com base na informação do Componente Gramatical. O Componente Contextual é alimentado por todos os níveis de representação, e as operações de formulação e de codificação são por ele alimentadas.

O Componente Gramatical contempla quatro níveis de análise que são estruturados hierarquicamente em camadas particulares a cada nível. No Nível Interpessoal (NI) estão as distinções de formulação relacionadas à interação entre falantes e ouvintes. A disposição hierárquica é demonstrada em (5) em que, quanto mais à esquerda, mais alta é a camada na hierarquia do nível correspondente.

$$
\left(M_{1}:\left[\left(A_{1}:\left[(F)\left(P_{1}\right)_{S}\left(P_{2}\right)_{A}\left(C_{1}:\left[\left(T_{1}\right)_{\Phi} \ldots\left(T_{1+N}\right)_{\Phi}\left[\left(R_{1}\right)_{\phi} \ldots\left(R_{1+N}\right)_{\Phi}\right]\left(C_{1}\right)_{\Phi}\right)\right]\left(A_{1}\right) \ldots\left(A_{1+N}\right)_{\Phi}\right]\left(M_{1}\right)\right)\right.\right.
$$
(HENGEVELD; MACKENZIE, 2008, p. 15).

A camada mais alta do Nível Interpessoal é a do Movimento (M), que é definido como uma porção textual que traz uma contribuição autônoma do falante para a interação e pode provocar ou ser ele mesmo uma reação. O Movimento é formado de um ou mais Atos Discursivos (A) que mantêm relações de dependência ou equipolência entre si. Quando há dependência, temos no ato subsidiário uma função retórica que pode ser de Motivação, de Concessão, de Orientação, de Correção (ou de Esclarecimento) e de Aposição. Um Ato Discursivo é composto por categorias não hierárquicas: Ilocução (F), Falante $\left(\mathrm{P}_{1}\right)$ e Ouvinte $\left(\mathrm{P}_{2}\right)$ que se alternam, e um Conteúdo Comunicado (C). Por sua vez, o Conteúdo Comunicado contém a totalidade daquilo que o falante deseja evocar na sua comunicação. Cada Conteúdo Comunicado contém um ou mais Subatos de Referência e/ou de Atribuição, que representam a evocação de um referente e de uma propriedade, respectivamente.

Na GDF, tanto a referência quanto a atribuição são vistas como acionais, já que envolvem tentativa do falante de influenciar a informação pragmática do ouvinte. Exatamente da mesma maneira que na referência, a escolha de itens lexicais e a quantidade de material lexical fornecidas na atribuição derivam da estimativa do falante de como influenciar mais eficazmente o interlocutor.

A distribuição dos Subatos de Referência e de Atribuição e a relação entre eles são cruciais para se compreender a constituição das aposições e as funções discursivas exercidas por elas, especialmente porque se podem atribuir as funções pragmáticas Tópico, Foco e Contraste a um Subato de Referência como um todo ou aos Subatos de Atribuição que o constituem. 
O Subato de Atribuição (T) é uma tentativa do falante de evocar uma propriedade, que se aplica, em geral, a um elemento referencial, mas, como afırmam Hengeveld e Mackenzie (2008), esse Subato não necessariamente atribui uma propriedade a um referente, já que é possível existirem Conteúdos Comunicados contendo apenas um Subato de Atribuição, como ilustrado em (6).

(6) Chove.

$$
\left(C_{1}:\left(T_{1}\right)\left(C_{1}\right)\right)
$$

Os Subatos de Atribuição podem aparecer dentro dos Subatos de Referência. No caso de um carro azul, por exemplo, temos um Subato de Referência correspondente ao SN todo que contém dois Subatos de Atribuição, que correspondem, no Nível Representacional, à propriedade ${ }^{5}$ carro e à propriedade azul, lugar da teoria em que se estabelece a relação de restrição entre azul e carro:

(7) Um carro azul.
$N I: \quad\left(R_{1}:\left[\left(T_{1}\right)\right.\right.$
$\left.\left(T_{\top}\right)\right]$
$\left.\left(R_{1}\right)\right)$
NR: $\left(x_{i}:\left(f_{i}\right)\right.$ : carro $\left.\left.\left(f_{i}\right)\right)\left(x_{i}\right):\left(f_{j}: \operatorname{azul}\left(f_{j}\right)\right)\left(x_{i}\right)\right)$

Enquanto o Subato de Atribuição evoca uma propriedade, o Subato de Referência evoca uma entidade. O núcleo do Subato de Referência pode ser um ou mais Subatos de Atribuição, um nome próprio ou um dummy , ou uma combinação abstrata de caraterísticas para o Falante e Ouvinte.

Fazem-se distinções no Nível Interpessoal que refletem o estatuto da referência como uma atividade interpessoal, isto é, distinções em termos de identificabilidade e especifıcidade da referência.

Estabelecem-se as distinções de identificabilidade e especificidade mediante o uso dos operadores [+ id, -id] e [+s, -s], respectivamente. A identificabilidade concerne às suposições do Falante sobre o conhecimento do Ouvinte, enquanto a especificidade, ao conhecimento do referente pelo próprio falante. Essas distinções, que aparecem

\footnotetext{
5 Para a GDF, categorias semânticas são designadas por Propriedades Lexicais, ou simplesmente Propriedades, que podem estar na posição de núcleo ou modificador (HENGEVELD; MACKENZIE, 2008). Em (7), as propriedades carro e azul são utilizadas para caracterizar um Indivíduo (x).

6 Elemento morfossintaticamente obrigatório inserido em uma posição (slot) da oração, mas que não corresponde a nenhum material lexical no Nível Interpessoal e no Nível Representacional, como os pronomes it e there do inglês (It is raining - Chove.; There is beer without alcohol. - Há cerveja sem álcool.) ou o pronome il do francês (II pleut. - Chove.).
} 
codificadas no Nível Morfossintático mediante o uso de artigos e pronomes demonstrativos, são particularmente relevantes para o estudo das aposições, pois, com base nelas, é possível determinar quais são os membros prototípicos ${ }^{7}$ no continuum das construções apositivas e mesmo o que motiva as escolhas de uma construção apositiva em detrimento do uso de apenas um ou outro termo do SN.

Aos Subatos podem-se atribuir três funções pragmáticas, Tópico, Foco e Contraste ${ }^{8}$, quando há alguma repercussão morfossintática ou fonológica deles na codificação. A função pragmática Tópico assinala que o Subato contém uma informação dada ou inferível. A função Foco sinaliza a seleção de uma informação nova pelo falante para preencher uma lacuna na informação do ouvinte ou para corrigir uma informação de que ele disponha. Por fim, a função de Contraste assinala o desejo do falante de salientar diferenças particulares entre os elementos dos Subatos.

Passemos, agora, a ver como se configura o Nível Representacional. Se, por um lado, o Nível Interpessoal é o responsável pela evocação, por outro, o Representacional se encarrega da designação, contemplando os aspectos semânticos da gramática de uma língua. Definem-se as camadas desse nível com base em categorias semânticas hierarquicamente organizadas em camadas, como mostra (8).

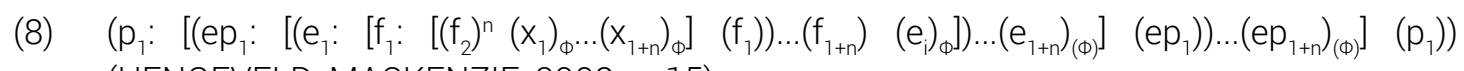
(HENGEVELD; MACKENZIE, 2008, p. 15).

A camada mais alta do Nível Representacional é a do Conteúdo Proposicional (p), que representa construtos mentais. A segunda camada na hierarquia é a do Episódio (ep), que contém um ou mais Estado de Coisas (e). A camada seguinte é a da Propriedade Configuracional (f), que constitui um molde de predicação, cuja construção depende de categorias semânticas não hierárquicas entre si, representando entidades como Indivíduo (x), Propriedade Lexical (f), Locação (l), Tempo (t), Maneira (m), Razão (r) e Quantidade (q).

O Nível Morfossintático (NM) trata de aspectos formais de uma unidade linguística. A arquitetura descendente da GDF mostra que muito do que acontece no NM é motivado pelos níveis da Formulação, ou seja, os níveis Interpessoal e Representacional. Mais acima, fornecemos uma ideia geral de como as funções pragmáticas são codificadas no Nível Morfossintático. As camadas relevantes desse nível estão dispostas em (9).

7 Entende Rosch (1973) que a categorização humana não é arbitrária, mas procede de exemplares mais centrais para exemplares mais periféricos de categorias, sendo prototípicos justamente os exemplares centrais que parecem mais salientes aos falantes.

8 As funções pragmáticas também podem ser atribuídas a Conteúdos Comunicados como um todo. Dada, porém, a natureza deste trabalho, convém tratar apenas da sua atribuição aos Subatos. 
(9) $\left(\mathrm{Le}_{1}:\left[\left(\mathrm{XW}_{1}\right)\left(\mathrm{Xp}_{1}\right)\left(\mathrm{Cl}_{1}:\left[\left(\mathrm{XW}_{2}\right)\left(\mathrm{Xp}_{2}:\left[\left(\mathrm{XW}_{3}\right)\left(\mathrm{Xp}_{3}\right)\left(\mathrm{Cl}_{3}\right)\right]\left(\mathrm{Xp}_{2}\right)\right)_{\Phi}(\mathrm{Cl})_{(\Phi)}\right]\left(\mathrm{Cl}_{1}\right)\right)\right]\left(\mathrm{Le}_{1}\right)\right)($ HENGEVELD; MACKENZIE, 2008, p. 17).

Uma Expressão Linguística (Le) é o conjunto de uma ou mais unidades morfossintáticas, constituindo o que na tradição gramatical se entende por sentença. Essas unidades linguísticas podem ser constituídas por Orações (Cl), Sintagmas (Xp) e finalmente Palavras (Xw), que, por sua vez, se compõem de uma Raiz (Xs) e de um Afixo (Aff).

O último nível de análise que compõe o Componente Gramatical é o Fonológico, que aparece representado em (10).

(10) $\quad\left(\mathrm{U}_{1}:\left[\left(\mathrm{IP}_{1}:\left[\left(\mathrm{PP}_{1}:\left[\left(\mathrm{PW}_{1}\right)\right]\left(\mathrm{PP}_{1}\right)\right)\right]\left(\mathrm{IP}_{1}\right)\right)\right]\left(\mathrm{U}_{1}\right)\right)($ HENGEVELD; MACKENZIE, 2008, p. 18).

A camada mais alta desse nível é o Enunciado (U), cujas fronteiras são marcadas por pausas mais longas do que as das Frases Entonacionais (IP). As Frases Entonacionais se caracterizam por um núcleo, isto é, um movimento tonal realizado em uma ou mais sílabas. A camada seguinte do Nível Fonológico é a da Frase Fonológica (PP). Assim como Frases Entonacionais normalmente correspondem a Atos Discursivos no NI, a Frase Fonológica mantém uma correspondência ainda que não estrita com os Subatos de Referência e de Atribuição. As Palavras Fonológicas (PW) se dividem em Sílabas (S), que se agrupam em pés ( $F$ ).

Seguir a arquitetura descendente do modelo significa que a análise a ser apresentada na seção 4 parte de critérios pragmáticos, passa por critérios semânticos e estabelece relações entre os dois níveis de Formulação correspondentes, o Nível Interpessoal e o Representacional, e o nível de Codificação, o Morfossintático. Dessa maneira, pretendese comprovar que aspectos da codificação morfossintática têm relevância teoricamente explanatória como um reflexo que são dos níveis mais altos; é justamente essa correlação que representa uma contribuição deste trabalho para confirmar os parâmetros da análise funcionalista, mais especificamente, do arcabouço Discursivo-Funcional.

\section{Distinção entre os tipos de aposição com base em correlações pragmáticas e semânticas}

Como já mencionado, a aposição restritiva é uma estrutura de sintagma nominal que, no Nível Interpessoal, corresponde a um único Subato de Referência $\left(R_{1}\right)$ e que, no Nível Representacional, tem o primeiro constituinte, geralmente um nome comum, modificado de maneira restritiva pelo segundo nome, que é, na maioria dos casos, expresso por um nome próprio ${ }^{9}$, conforme formalizado em (11).

9 Adotamos aqui a formalização proposta por Keizer (2008) para os nomes próprios em sintagmas apositivos. 

(11) $\quad \mathrm{Nl}:\left(+i d R_{1}:\left(T_{1}\right)\right.$
$\left(T_{\jmath}\right)$
$\left.\left(R_{1}\right)\right)$
NR: $\left(\mathrm{x}_{\mathrm{i}}: \quad\left(\mathrm{f}_{\mathrm{i}}\right.\right.$ presidente $\left.\left(\mathrm{f}_{\mathrm{i}}\right)\right):\left(\mathrm{x}_{\mathrm{j}}\right.$ : Lula $\left.\left.\left(\mathrm{x}_{\mathrm{j}}\right)\right)\left(\mathrm{x}_{\mathrm{i}}\right)\right)$
O ex-presidente Lula

No caso de aposições restritivas com de, como a cidade de São Paulo, a relação de modificação no Nível Representacional segue a mesma direção, em que a cidade é o núcleo e de São Paulo é um modificador que dá uma especificação semanticamente necessária (12).
(12) NI: (+id $R_{1}:\left(T_{1}\right)$
$\left.\left(T_{J}\right) \quad\left(R_{1}\right)\right)$

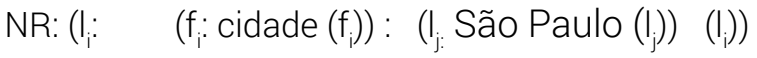
A cidade de São Paulo

Diferentemente desse tipo de estrutura, as aposições não restritivas são constituídas por dois SNs, cada um correspondendo a um Subato de Referência no Nível Interpessoal. Esses dois SNs são semanticamente correferenciais, o que significa que, no Nível Representacional, referem-se a apenas uma entidade $\left(x_{i}\right)$ em (13).

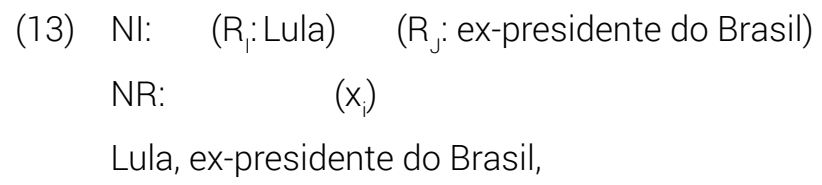

É possível associar as aposições restritivas a sentenças copulares, de modo tal que, um exemplo como (11) poderia ter como correspondente oracional Lula é ex-presidente e a aposição em (12) o correspondente A cidade é São Paulo.

Raposo e Nascimento (2013) afirmam que, nas construções do padrão substantivo + (de) + nome próprio, o substantivo, denominado pelos autores como classificador, pode ocorrer como sujeito de uma oração tendo o verbo chamar-se (ou equivalente) como predicador, como se vê nos exemplos contidos em (14-15).
a Livraria Bertrand
b Essa livraria se chama Bertrand
a O mês de janeiro
b Esse mês se chama janeiro 
A possibilidade de paráfrases do tipo [N2 é N1] (Lula é ex-presidente) e [N1 chama-se N2] (o ex-presidente chama-se Lula) ativa duas características das aposições restritivas: a atribuição de um título, função ou descrição para definir uma entidade, no caso das sentenças copulares, e a atribuição de um nome para essa mesma entidade, no caso da paráfrase com o verbo chamar. Essas propriedades garantem que a aposição restritiva tenha uma referência inequívoca.

No entanto, em termos discursivo-funcionais, não seria possível atribuir a uma construção com o predicado chamar-se um padrão de predicado do tipo classificacional, como em Lula é ex-presidente, nem identificacional, como Lula é o ex-presidente.

De acordo com Hengeveld e Mackenzie (2008), na classificação, o Nível Interpessoal contém uma relação entre um Subato de Atribuição e um Subato de Referência, enquanto, no Nível Representacional, o padrão do predicado consiste em duas unidades semânticas ontologicamente idênticas, pela simples razão de que um Indivíduo (x) pode classificar-se somente como outro Indivíduo (x), e não - a não ser metaforicamente - como um estado de coisas (e) (João é explosão) ou uma Propriedade Lexical (f) (João é alta temperatura).

Como a entidade envolvida se submete a uma classificação, ela assume a função semântica de Inativo (Undergoer). O padrão que especifica as funções semânticas no predicado classificacional básico está contido em (16) em que ' $v$ ' é uma variável sobre variáveis, para representar a possibilidade de conter um Indivíduo (x), um Estado de Coisas (e) ou uma Propriedade (f). Insere-se a cópula no Nível Morfossintático.

$$
\begin{array}{cc}
T & R \\
\left(f_{1}:\left[\begin{array}{ll}
\left(v_{1}\right) & \left(v_{2}\right)_{U}
\end{array}\right]\left(f_{1}\right)\right) & (\text { HENGEVELD; MACKENZIE, 2008, p. 204). }
\end{array}
$$

Considerado, portanto, o valor relevante do SN O ex-Presidente Lula, a paráfrase que permite uma leitura mais adequada dele é a que corresponde ao predicado não referencial Lula é ex-presidente, uma vez que, na aposição restritiva 0 ex-presidente Lula, é ex-presidente que evoca a atribuição de uma propriedade ao referente pretendido, Lula, de modo a reafirmar o título, a função institucional ou a descrição que define o indivíduo a que a aposição o presidente Lula se refere.

Se produzirmos a outra paráfrase possível, 0 ex-presidente é Lula, surgem duas sérias inadequações: em primeiro lugar, a expressão atributiva ex-presidente da formulação original deixa de ter valor atributivo para adquirir valor referencial, o que como consequência requer a introdução de identificabilidade codificada pelo artigo definido no Nível Morfossintático. Em segundo lugar, a relação de identificação indicaria equivocadamente que há dois Subatos de Referência em 0 ex-presidente Lula, o que 
absolutamente não corresponde à verdadeira intenção comunicativa da formulação de uma aposição restritiva. O mesmo vale para a paráfrase sugerida por Raposo e Nascimento (2013) com o verbo chamar-se, mas que é aceitável somente numa leitura identificacional, e não uma classificacional, que é própria da aposição restritiva. É por essa razão que só admitimos a paráfrase Lula é ex-presidente, mas não seu reverso 0 expresidente é Lula, e, na versão daqueles autores, 0 ex-presidente se chama Lula.

Com efeito, a relação equativa se dá entre duas entidades referenciais, codificada numa construção identificacional, como em (17)

$$
\left.\left.\begin{array}{cl}
R & R \\
\left(f_{1}:\left[\left(x_{1}\right)\right.\right. & \left(x_{1}\right)
\end{array}\right]\left(f_{1}\right)\right)(\text { HENGEVELD; MACKENZIE, 2008, p. 205). }
$$

Numa construção identificacional, duas unidades semânticas representam meios alternativos de ver a mesma entidade. Não há relação de atribuição de propriedade e, por isso, nenhuma das duas unidades contrai uma função semântica, como ocorre com a atribuição de Inativo à construção classificacional. Na realidade, o teste da formulação copulativa, com construção de identificação, seria mais adequadamente aplicável a uma aposição não restritiva, como a expressa em (18).

$$
\begin{aligned}
& \text { (18) a Lula, o presidente dos pobres } \\
& \text { b Lula é o presidente dos pobres. } \\
& \text { c O presidente dos pobres é Lula. }
\end{aligned}
$$

As aposições restritivas sem operador de definitude não licenciam também construções equativas, como as aposições não restritivas, deixando ainda mais direta a relação entre os constituintes e, por isso, não admite a construção identificacional com dois Subatos Referenciais, como mostram os exemplos contidos em (19-20).

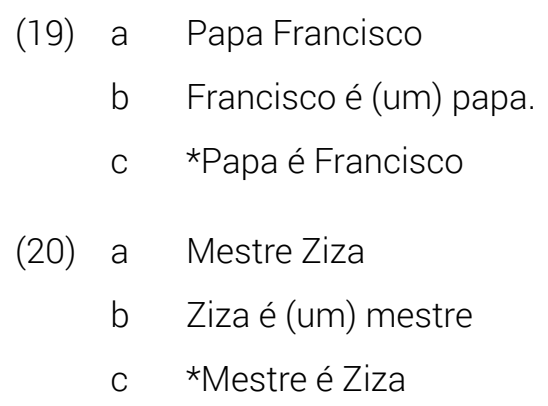


Nos casos acima, o não licenciamento de paráfrases com construção identificacional em (19c) e (20c) mostra ser obrigatória a leitura de evocação de uma atribuição, ou seja, o SN representando aposições restritivas evoca um Subato de Referência (Ziza) e um Subato de Atribuição, justamente o classificador (mestre).

Esse tipo se aproxima do padrão em que núcleo e modificador são conectados por preposição, como a cidade de Santos. Para Raposo e Nascimento (2013), a relação, que é identificacional, responderia pela paráfrase A cidade se chama Santos, o que, nesse caso, seria um equivalente perfeito de $A$ cidade é Santos, que, similarmente a Mestre Ziza, é uma construção classificacional, tendo como a paráfrase mais provável uma relação sujeito/ predicado invertida, que, se comparada a Mestre Ziza (Ziza é mestre), seria a cidade é Santos.

Comporta-se similarmente a essa aposição outros padrões como o conceito de proletariado, a que se aplica como paráfrase mais provável, o conceito é proletariado em face da leitura metalinguística de proletariado. Nesses dois padrões específicos, além da diferença semântica, a distinção se dá na codificação morfossintática. A similaridade semântica entre a cidade de Santos e o conceito de proletariado leva a uma construção classificacional, mas de paráfrase invertida a Mestre Ziza, se aplicado o teste da predicação copulativa.

Essa similaridade tem fundamento na diacronia do português em que se veem resíduos de outras etapas da mudança: mês janeiro pode emergir lado a lado com mês de janeiro e tem em a letra 'e', o número cinco etc. suas construções prototípicas, cuja paráfrase é motivação, uma vez mais, para uma construção classificacional: a letra é 'e', o número é "cinco" etc. (MAURER JUNIOR, 1959).

Revistas as correlações semânticas, vejamos agora como explicar a diversidade funcional das construções apositivas na construção do texto. Considere-se inicialmente o exemplo (21).

(21) Tem sido assim desde sua chegada em companhia do marido, o escultor Hissao Ohara, morto em 1989. (858 R 10-11).

A ocorrência acima traz uma aposição restritiva e outra não restritiva em diferentes linearizações. No exemplo (21), uma aposição não restritiva (o escultor Hissao Ohara) é aposto de marido, imediatamente anterior. É curioso que uma aposição não restritiva seja constituída em si mesma por uma aposição restritiva sem preposição, o que caracteriza a liberdade de criação do sujeito no processo de interação. 
É o segundo membro da aposição não restritiva que fornece uma informação relevante sobre o referente do primeiro membro, elaborando a referência, o que não acontece nas restritivas. No caso de (21), marido e o escultor Hissao Ohara constituem dois Subatos de Referência, sendo o segundo Subato um desenvolvimento do primeiro. Ao mesmo tempo, na aposição restritiva o escultor Hissao Ohara, vê-se a relevância no Nível Representacional em inserir um predicado modificador para o nome próprio que o identifica como um tipo de artista, outra informação relevante no contexto da enunciação.

Vejamos agora o exemplo (22).

Foi na Escola Ultramarina, cristã, que se matriculou o rapagão Issamu Yuba (1906-1976), filho do prefeito de uma cidade da Baía de Osaka inconformado com a escalada da desigualdade social. (858 R 10-11).

Nesse caso, a linearização no Nível Morfossintático reproduz outra estratégia do falante em que uma aposição restritiva (o rapagão Issamu Yuba (1906-1976)) inicia a referência a uma entidade, que acaba recebendo mais especificação pela aposição não restritiva imediatamente seguinte. No caso de o rapagão Issamu Yuba, o falante atribui uma propriedade, rapagão, que é uma avaliação de si próprio sobre o referente. É um uso mais periférico de uma aposição restritiva que veicula não exatamente uma modificação informacionalmente relevante, mas uma avaliação subjetiva vinculada ao polo da enunciação.

Vejamos agora o exemplo (23).

(23) Sobram casos de perseguição da farda à batina. Dom Helder Câmara, um dos fundadores da CNBB em 1952, arcebispo emérita de Olinda e Recife, era proibido de ser citado na mídia. Padre Antonio Henrique Pereira Neto, seu amigo e assessor, foi sequestrado, torturado e morto em 1969 por agentes da ditadura, como forma de intimidar dom Helder. (1042 R 20).

Em (23), retoma-se o referente de Dom Helder Câmara, um subtópico do supertópico Farda e Batina, em duas aposições sucessivas antes de emergir a informação focal (era proibido de ser citado na mídia). Na sequência, o subtópico passa a ser o referente de Padre Antonio Henrique Pereira Neto, uma aposição restritiva, retomada por uma terceira aposição não restritiva (seu amigo e assessor), que o vincula anaforicamente ao subtópico disparado no início do fragmento de texto em análise e explica como os agentes da ditadura intimidavam o aparecimento de Dom Helder Câmara na mídia. O que vai tornar Padre Antonio Henrique Pereira Neto um subtópico evocado não é o elemento descritivo Padre, mas a aposição não restritiva seguinte que o vincula ao subtópico principal Dom Helder Câmara por meio de seu amigo e assessor. 


\section{Considerações finais}

Ao analisar e descrever as aposições restritivas sem e com a preposição de no português escrito, levantamos como relevante o objetivo de identificar parâmetros de formulação e de codificação que oponham e/ou aproximem as aposições restritivas sem e com elemento de ligação nos níveis relevantes.

Adotou-se como aparato teórico fundamental a Gramática Discursivo-Funcional (GDF), um modelo que postula uma orientação descendente para a gramática que, tomando como ponto de partida a intenção comunicativa, desenvolve-se em níveis de formulação e de codificação para chegar, enfim, à articulação. Esse modelo toma como pressuposto que uma teoria da gramática é tanto mais adequada quanto mais se espelhar no modelo de processamento linguístico do falante. Admitir uma arquitetura descendente significa assumir que os níveis de formulação, ou seja, o Interpessoal e o Representacional motivam a codificação morfossintática e fonológica de uma expressão linguística.

O procedimento metodológico aplicado procurou distinguir, por um lado, a aposição não restritiva dos diferentes tipos de aposição restritiva com base na representação formal das construções identificacionais e, por outro, os subtipos de aposição restritiva com base no tipo de relação copulativa que elas permitem estabelecer, tendo como critério a representação das construções classificacionais. Um correlato significativo do caráter semanticamente identificacional das aposições não restritivas está no fato de representarem dois Subatos de Referência no Nível Interpessoal, o que mostra claramente que a GDF acaba produzindo parâmetros suficientes e necessários para a identificação de cada tipo.

Observadas as diferenças na utilização das aposições restritivas e não restritivas, voltamos a atenção para a diferença entre as restritivas sem e com o elemento de ligação de em sua constituição. No Nível Interpessoal, os dois tipos constituem, diferentemente da aposição não restritiva, um único Subato de Referência e que, por sua vez, contém dois Subatos de Atribuição. As aposições sem preposição podem ser marcadas ou não por definitude, enquanto as com de são necessariamente definidas. O que mais adequadamente identifica as aposições restritivas sem de é uma paráfrase com uma atribuição de propriedade, diferentemente das oposições não restritivas, que podem ser parafraseadas semanticamente como uma construção identificacional. Algumas construções sem artigo como Mestre Ziza são mais adequadamente identificadas com uma construção classificacional.

Fazendo um balanço ligeiro das aproximações e das distinções, é possível concluir que a aplicação de parâmetros extraídos do arcabouço teórico da GDF demonstrou que o modelo tem alto poder explanatório e torna-se um modelo adequado para a análise dos aspectos semânticos e morfossintáticos das aposições. 


\section{REFERÊNCIAS}

BECHARA, E. Moderna gramática portuguesa. 37. ed. Rio de Janeiro: Nova Fronteira, 2009.

CUNHA, C.; CINTRA, L. F. L. Nova gramática do português contemporâneo. 5. ed. Rio de Janeiro: Lexikon, 2008.

FRANCIS, W. N. The structure of American English. New York: Ronald, 1958.

HENGEVELD, K. Introduction: transparency in Functional Discourse Grammar. Linguistics in Amsterdam, Amsterdam, v. 4, n. 2, p. 1-22, 2011.

HENGEVELD, K.; MACKENZIE, J. L. Functional Discourse Grammar: a typologically-based theory of language structure. Oxford: Oxford University Press, 2008.

HOCKETT, C. F. Attribution and apposition in English. American Speech, Durham, v. 30, p. 99-102, 1955.

KEIZER, E. Close appositions. In: GROOT, C.; HENGEVELD, K. (ed.). Morphosyntactic expression in Functional Grammar. Berlin: Mouton de Gruyter, 2005. p. 381-418.

KURY, A. G. Novas lições de análise sintática. São Paulo: Ática, 2011.

LAGO, J. A special type of nonrestrictive modification: the apposition. Verba: anuario galego de filoloxía, Santiago Compostela, v. 18, p. 487-520, 1991.

LEMSON, T. M. S. C. Aposições restritivas no português brasileiro escrito contemporâneo: análise e formalização no modelo da gramática discursivo-funcional. 2016. Tese (Doutorado em Linguística) - Centro de Humanidades, Universidade Federal do Ceará, Fortaleza, 2016.

LONGRÉE, D. Les compléments du nom en latin classique: syntaxe, sémantique et pragmatique. Cahiers de L'Institut de Linguistique de Louvain, Louvain, v. 13, n. 1/2, p. 163230, 1987.

MATTHEWS, P. H. Syntax. Cambridge: Cambridge University Press, 1981.

MAURER JUNIOR, T. H. Gramática do latim vulgar. Rio de Janeiro: Acadêmica, 1959. 
MEYER, C. F. Apposition in Contemporary English. Cambridge: Cambridge University Press, 1992.

NOGUEIRA, M. T. Propriedades textuais-discursivas da aposição não restritiva. In: SOUZA, E. R. Funcionalismo linguístico: análise e descrição. São Paulo: Editora Contexto, 2012. p. 147-169.

NOGUEIRA, M. T. Construção apositiva e recategorização metafórica. Veredas, Juiz de Fora, v. 15, n. 2, p. 179-189, 2011.

NOGUEIRA, M. T. A aposição não-restritiva em textos do português contemporâneo escritos no Brasil. 1999. Tese (Doutorado em Linguística e Língua Portuguesa) - Faculdade de Ciências e Letras, Universidade Estadual Paulista "Júlio de Mesquita Filho", Araraquara, 1999.

QUIRK, R. S. et al. A comprehensive grammar of the English language. London: Longman, 1985.

RAPOSO, E. B. P.; NASCIMENTO, M. F. B. Nomes próprios. In: RAPOSO, E. B. P.; NASCIMENTO, M. F. B.; MOTA, M. A. C.; SEGURA, M.; MENDES, A. (org.). Gramática do português. Coimbra: Fundação Calouste Gulbenkian, 2013. v. 1. p. 993-1044.

RODRÍGUEZ, C. F. De nuevo sobre la aposición. Verba: anuario galego de filoloxía, Santiago Compostela, v. 16, p. 215-236, 1989.

ROSCH, E. H. Natural categories. Cognitive Psychology, New York, v. 4, p. 328-350, 1973.

SERAFIM, M. C. S. Aposições restritivas no português escrito. 2019. Dissertação (Mestrado) - Instituto de Biociências, Letras e Ciências Exatas, Universidade Estadual Paulista "Júlio de Mesquita Filho", São José do Rio Preto, 2019.

TABOADA, M. Relaciones sintácticas en el interior de la frase nominal: la aposición. Verba: anuario galego de filoloxía, Santiago Compostela, v. 5, p. 315-340, 1978.

TESNIÈRE, L. Éléments de syntaxe structurale. Paris: Librairie C. Klincksieck, 1965. 